\title{
Czy można bezpośrednio po związaniu materiału Biodentine przystąpić do odtworzenia tkanek zęba z zastosowaniem systemu samotrawiącego?
}

\section{Is it possible to immediately proceed to restore tooth structure using a self-etching adhesive system after Biodentine setting?}

\author{
Katarzyna Kot ${ }^{1 凶}$, Alicja Nowicka ${ }^{2}$, Mariusz Lipski ${ }^{1}$ \\ 1 Pomorski Uniwersytet Medyczny w Szczecinie, Katedra i Zakład Stomatologii Zachowawczej Przedklinicznej i Endodoncji Przedklinicznej, al. Powstańców Wlkp. 72, \\ 70-111 Szczecin \\ ${ }_{2}^{2}$ Pomorski Uniwersytet Medyczny w Szczecinie, Katedra i Zakład Stomatologii Zachowawczej i Endodoncji, al. Powstańców Wlkp. 72, 70-111 Szczecin \\ $\triangle$ katarzynakot84@tlen.pl
}

\begin{abstract}
Introduction: Biodentine is a bioactive dentin substitute which be used to cover the exposed pulp, and for simultaneous dentin reconstruction during a single visit.

The aim of this study was to evaluate cavity walls which were covered by an adhesive system directly after the setting of Biodentine ( $15 \mathrm{~min}$. after its mixing), and $24 \mathrm{~h}$ after setting in a scanning electron microscope.

Materials and methods: Six extracted human premolars were used in this study. Black's I class cavity were prepared on the occlusal surface. The bottom of the cavities was covered with Biodentine. The teeth were then divided into 2 groups of 3 teeth each. In group 1, the Prelude adhesive system (Danville, USA) was used $15 \mathrm{~min}$. after the mixing of Biodentine. In group 2, the same procedure was applied after $24 \mathrm{~h}$.
\end{abstract}

Results: Scanning electron mikroscope (SEM) examination of the cavity walls in group 1 showed the presence of numerous particles covering the surface of the dentin and enamel. Energy dispersive spectrometry (EDS microanalysis) confirmed the presence of silicon and aluminium, which are components of Biodentine. In group 2, the walls of the cavity were free from contamination. Energy dispersive spectrometry analysis revealed the presence of elements typical of dental tissue.

Conclusions: Biodentine does not set sufficiently after $15 \mathrm{~min}$. after mixing, so an adhesive system cannot be safely used when Biodentine is applied as a base.

Keywords: Biodentine; self-etching adhesive systems; SEM; EDS microanalysis.

\begin{abstract}
ABSTRAKT
Wstęp: Materiał Biodentine nazywany jest bioaktywnym substytutem zębiny i może być stosowany do przykrycia odsłoniętej miazgi i jednoczesnej odbudowy zębiny w tzw. metodzie jednoseansowej.

Celem pracy była ocena w elektronowym mikroskopie skaningowym ścian ubytku, na które zastosowano system wiążący bezpośrednio po związaniu materiału Biodentine (po 15 min od jego przygotowania) oraz po 24 godz. od jego związania.

Materiały i metody: Do badania posłużyło 6 ludzkich zębów przedtrzonowych, w których na powierzchni żującej wypreparowano ubytki kl. I Blacka. Dno ubytków przykryto materiałem Biodentine. Następnie zęby podzielono na 2 grupy po 3 zęby w każdej. W grupie I, po upływie 15 min od momentu przygotowania materiału Biodentine, zastosowano system wiążący
\end{abstract}

Prelude (Danville, USA). W grupie II zastosowano identyczną procedurę po 24 godz.

Wyniki: Obserwacje ścian ubytku wykonane w skaningowym mikroskopie elektronowym (SEM) wykazały w grupie I obecność licznych drobin pokrywających powierzchnię zębiny i szkliwa. Mikroanaliza spektroskopii dyspersji energii (energy dispersive spectromerty-EDS) potwierdziła m.in. obecność krzemu i glinu występujących w materiale Biodentine. W grupie II ściany ubytku były wolne od zanieczyszczeń. Analiza EDS wykazała obecność pierwiastków typowych dla tkanek zęba.

Wnioski: Materiał Biodentine po $15 \mathrm{~min}$ od przygotowania nie ulega związaniu w takim stopniu, by można było bezpiecznie stosować system wiążący w przypadku użycia Biodentine jako podkładu.

Słowa kluczowe: Biodentine; systemy wiążące; SEM; mikroanaliza EDS.

\section{WSTĘP}

Dzięki wykorzystaniu wiedzy na temat zjawiska adhezji faktem stało się wprowadzenie nowych technologii odtwórczych i przełamanie wielu barier ograniczających postęp w materiałoznawstwie stomatologicznym. To właśnie dokonania w dziedzinie adhezji okazały się motorem rewolucyjnych zmian otwierających nowe możliwości terapeutyczne w stomatologii. Ostatecznym celem adhezyjnego połączenia rekonstrukcji z tkankami zęba jest osiągnięcie ścisłej adaptacji materiału odtwórczego do tkanek zęba. Zadanie to jest trudne z racji odmiennych właściwości wiążących dla szkliwa w porównaniu z zębiną $[1,2]$. 
W ciągu wielu lat wprowadzano kolejne generacje systemów wiążących, różniących się przede wszystkim mechanizmem działania [3, 4]. Najnowsze osiągnięcie w dziedzinie stomatologicznych środków adhezyjnych oparte jest na uproszczeniu i skróceniu czasu aplikacji środka. Samotrawiące systemy adhezyjne nie wymagają wytrawiania oddzielnym preparatem kwasowym, gdyż jednocześnie uzdatniają i przygotowują one szkliwo i zębinę poprzez infiltrację i częściowe rozpuszczanie warstwy mazistej i hydroksyapatytu z wytworzeniem warstwy hybrydowej [5, 6, 7].

W 1993 r. do leczenia stomatologicznego wprowadzono preparat ProRoot MTA (Dentsply Maillefer, USA), który znalazł zastosowanie podczas zabiegu przykrycia pośredniego i bezpośredniego, pulpotomii częściowej i całkowitej, a także zamykania perforacji korzenia oraz wstecznego wypełniania kanału korzeniowego [8, 9, 10, 11]. Obecnie na rynku jest wiele produktów o zbliżonej do pierwowzoru budowie i w związku z powyższym właściwościach chemicznych i fizycznych. Ponieważ materiały te wiążą w ciągu kliku godzin, dalsze leczenie (leczenie endodontyczne, odbudowa korony zęba) może być kontynuowane dopiero podczas kolejnej wizyty. Ostatnio na rynku pojawiły się nowe materiały o biozgodności MTA, lecz pozbawione jego wad. Jednym z nich jest materiał Biodentine (Septodont, Francja), który składa się z proszku i płynu. Proszek zawiera głównie krzemian trójwapniowy $\left(3 \mathrm{CaO} \cdot \mathrm{SiO}_{2}\right)$, węglan wapnia $\left(\mathrm{CaCO}_{3}\right)$ i dwutlenek cyrkonu $\left(\mathrm{ZrO}_{2}\right)$. Płyn zawiera wodny roztwór chlorku wapnia $\left(\mathrm{CaCl}_{2}\right)[12,13,14]$. Czas wiązania Biodentine wynosi ok. 12 min. Ze względu na szybki czas wiązania, zgodnie z zaleceniami producenta, jak i niektórych autorów, może być stosowany do przykrycia odsłoniętej miazgi i jednoczesnej odbudowy zębiny w tzw. metodzie jednoseansowej, gdy odbudowa korony, np. z użyciem systemu wiążącego i materiału złożonego, następuje na tej samej wizycie, bezpośrednio po związaniu materiału, tj. po ok. 12-15 min [15, 16].

Własne spostrzeżenia kliniczne sugerują niezadowalający stopień związania materiału Biodentine po upływie podawanego przez producenta czasu, co może mieć wpływ na jakość rekonstrukcji wykonanej podczas tej samej wizyty.

Celem pracy była ocena w elektronowym mikroskopie skaningowym ścian ubytku, na które zastosowano system wiążący bezpośrednio po związaniu materiału Biodentine (po 15 min od jego przygotowania) oraz po 24 godz. od jego związania.

\section{MATERIAŁY I METODY}

Do badania posłużyło 6 ludzkich zębów przedtrzonowych usuniętych ze względów ortodontycznych. Bezpośrednio po ekstrakcji korony zębów odcięto na wysokości szyjki zęba. Następnie w obrębie powierzchni żującej wypreparowano ubytki $\mathrm{kl}$. I wg Blacka ze ścianami ustawionymi rozbieżnie w kierunku wejścia do ubytku (tak jak pod wkład koronowy). Preparacji dokonano z użyciem wierteł diamentowych w kształcie kulki osadzonych w kątnicy wiertki turbinowej oraz wierteł węglikowych osadzonych w kątnicy mikrosilnika. W trakcie preparacji stosowano chłodzenie wodnopowietrzne. Ogółem wypreparowano 6 ubytków o głębokości 4-5 mm, których dno przykryto materiałem Biodentine. Materiał wprowadzano do ubytku za pomocą pistoletu używanego do aplikacji amalgamatu, starając się nie dotknąć ścian ubytku. Po umieszczeniu materiał lekko kondensowano za pomocą upychadła kulkowego. Następnie zęby podzielono na 2 grupy po 3 zęby w każdej.

W grupie I, po upływie 15 minut od momentu przygotowania materiału Biodentine, na nieprzykrytą materiałem zębinę, jak i szkliwo zastosowano system wiążący Prelude (Danville, USA). Prelude Primer zgodnie z zaleceniami producenta wcierano przez $10 \mathrm{~s}$, unikając kontaktu aplikatora z materiałem Biodentine i delikatnie rozdmuchano powietrzem. Następnie przez 10 s wcierano Prelude Adhesive, rozdmuchano powietrzem i naświetlano lampą polimeryzującą The Cure Cordless II (Spring, USA) przez $10 \mathrm{~s}$.

W grupie II zastosowano identyczną procedurę, z tym że zabieg odroczono o 24 godz., umieszczając zęby na ten okres w szczelnie zamkniętym pojemniku.

W dalszej kolejności dokonano obserwacji w elektronowym mikroskopie skaningowym środowiskowym JSM 5600LV (Jeol, Japonia). Wybrane ściany ubytku obejrzano w powiększeniu 550x oraz dokonano mikroanalizy spektroskopii dyspersji energii (energy dispersive spectromerty - EDS) wybranych obszarów.

\section{WYNIKI}

W grupie I podczas aplikacji Prelude Primer zaobserwowano nieuzbrojonym okiem, że w wyniku niezamierzonego kontaktu tego preparatu z materiałem Biodentine (primer spływał na materiał) powstawała zawiesina. Zastosowanie lekkiego strumienia powietrza powodowało jej rozprowadzenie po powierzchni ścian ubytku i prawdopodobnie odparowanie rozpuszczalnika. Podczas aplikacji Prelude Adhesive nie obserwowano gołym okiem jakichkolwiek reakcji. Powierzchnia ściany ubytku sprawiała wrażenie czystej.

W grupie II, zarówno podczas aplikacji Prelude Primer, jak i Prelude Adhesive, nie obserwowano nieuzbrojonym okiem jakichkolwiek interakcji. I w tej grupie po spolimeryzowaniu systemu wiążącego ściana sprawiała wrażenie czystej.

Obserwacje ścian ubytku wykonane w skaningowym mikroskopie elektronowym (SEM) wykazały w grupie I obecność licznych drobin pokrywających powierzchnię zębiny i szkliwa (ryc. 1). Mikroanaliza EDS potwierdziła m.in. obecność krzemu i glinu występujących w materiale Biodentine (ryc. 2).

W grupie II ściany ubytku były wolne od tego typu zanieczyszczeń (ryc. 3). Analiza EDS wykazała obecność pierwiastków typowych dla tkanek zęba (ryc. 4). Sporadycznie wykrywano piki dla krzemu.

\section{DYSKUSJA}

Ze względu na właściwości mechaniczne zbliżone do zębiny materiał Biodentine nazywany jest bioaktywnym substytutem zębiny $[17,18,19]$. Charakteryzuje się dobrą twardością, dużą 


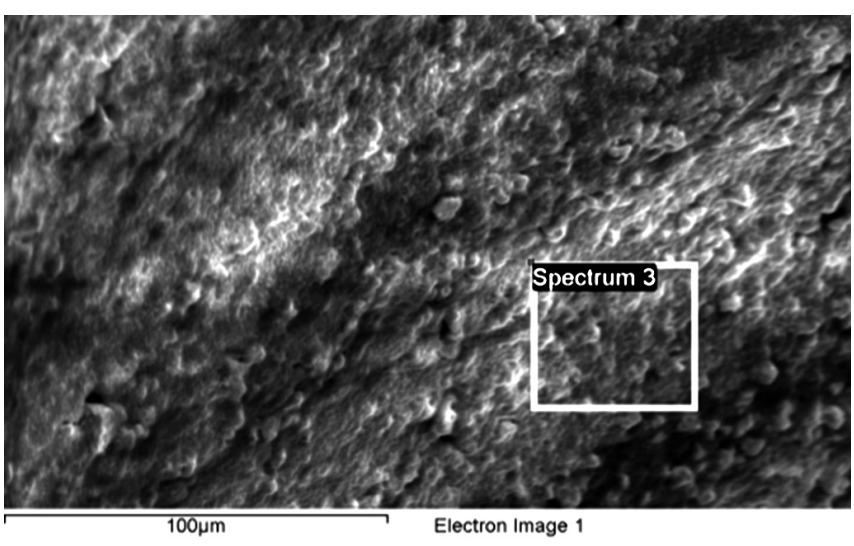

RYCINA 1. Powierzchnia ścian ubytku w grupie I. Widoczne liczne zanieczyszczenia

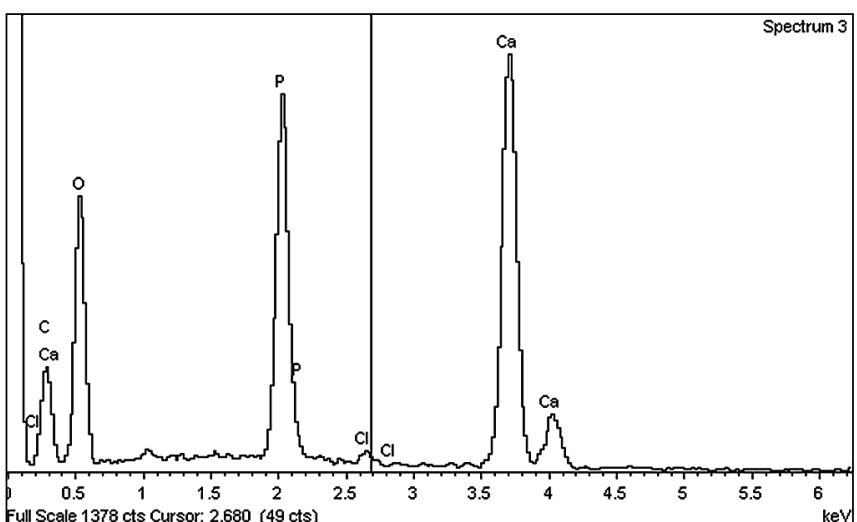

RYCINA 2. Mikroanaliza spektroskopii dyspersji energii z obszaru zaznaczonego na rycinie 1 (Spectrum 3). Obecność krzemu i glinu wstępującego w materiale Biodentine

gęstością i małą porowatością, a także wytrzymałością na ściskanie i zgniatanie $[15,16,18]$. Dodatkową zaletą Biodentine jest czas wiązania (ok. $12 \mathrm{~min}$ ). Należy jednak zwrócić uwagę, iż po upływie tego czasu materiał nie posiada wystarczającej twardości, którą osiąga dopiero po 30 dniach. Jednak zgodnie z zaleceniami producenta materiał Biodentine bezpośrednio po związaniu, tj. po 12 min od rozrobienia, może zostać pokryty warstwą materiału złożonego po wcześniejszym zastosowaniu odpowiedniego czynnika łączącego.

Najważniejszym czynnikiem mającym wpływ na trwałość i przewidywalność odbudowy z użyciem systemu wiążącego jest wytrzymałość połączenia pomiędzy wypełnieniem a szkliwem/zębiną, a także pomiędzy materiałem odtwórczym a podkładem [20, 21]. Na wielkość wytrzymałości połączenia pomiędzy zębiną a materiałem kompozytowym ma wpływ kilka czynników, tj.: właściwości samego materiału złożonego, rodzaj systemu wiążącego oraz jakość warstwy hybrydowej, która odpowiedzialna jest za zmniejszenie nadwrażliwości pozabiegowej, polepszenie szczelności brzeżnej, a także kompensację siły skurczu polimeryzacyjnego materiału kompozytowego podczas polimeryzacji [22, 23]. W badaniu własnym w przypadku grupy I ocena w mikroskopie skaningowym wykazała obecność licznych drobin pokrywających powierzchnię zębiny i szkliwa. Mikroanaliza EDS wykazała obecność

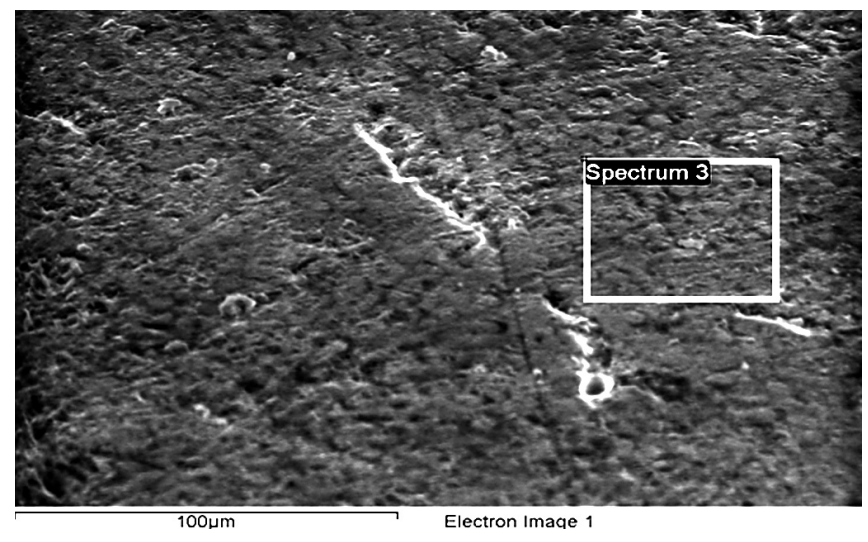

RYCINA 3. Powierzchnia ścian ubytku w grupie II. Brak widocznych zanieczyszczeń

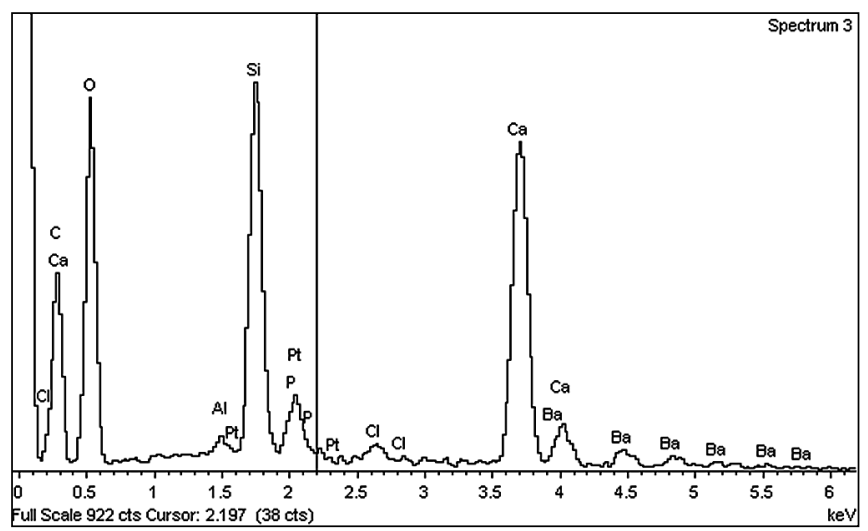

RYCINA 4. Mikroanaliza spektroskopii dyspersji energii z obszaru zaznaczonego na ryc. 3 (Spectrum 3). Obecność pierwiastków występujących w tkankach zęba

m.in. krzemu i glinu. Pierwiastki te nie występują w tkankach zęba, natomiast wchodzą w skład materiału Biodentine, co sugeruje, że zaobserwowane w grupie I zanieczyszczenia to drobiny materiału Biodentine. Zanieczyszczenie warstwy hybrydowej niewidocznymi gołym okiem drobinami materiału Biodentine może negatywnie wpłynąć na jakość połączenia materiału złożonego z tkankami zęba; w tym celu niezbędne jest przeprowadzenie odrębnego badania. Natomiast opisywanych zanieczyszczeń nie obserwowano na ścianach ubytku w grupie II, tj. w przypadku, gdy system wiążący zastosowano po 24 godz. od przygotowania materiału. Powyższe obserwacje jak i fakt, iż analiza EDS nie wykazała obecności na ścianach ubytku obecności pierwiastków wchodzących w skład Biodentine (sporadycznie rejestrowano piki dla krzemu), sugerują, że zastosowany w badaniu materiał wiąże po 24 godz. w stopniu uniemożliwiającym interakcje zachodzące w przypadku ew. kontaktu primera z cementem świeżo rozrobionym.

Od dłuższego czasu trwają prace nad poprawieniem adhezji materiałów kompozytowych zarówno do szkliwa, jak i zębiny poprzez unowocześnienie i udoskonalenie systemów wiążących. Samotrawiące systemy adhezyjne nie wymagają wytrawiania oddzielnym preparatem kwasowym, gdyż w swoim składzie zawierają wodne roztwory kwasowych monomerów, które są odpowiedzialne za przygotowanie powierzchni 
szkliwa i zębiny $[3,4,5,6,7]$. Do tej pory pojawiły się jedynie nieliczne publikacje dotyczące wpływu wytrawiania kwasem fosforowym na strukturę i właściwości mechaniczne materiału MTA [24, 25] oraz Biodentine [12, 26]. W przypadku MTA wytrawienie powierzchni $37 \%$ kwasem fosforowym po 4 godz. od rozrobienia materiału w znaczący sposób obniżyło wytrzymałość materiału na ściskanie oraz zmniejszyło jego mikrotwardość w porównaniu z grupą, w której do aplikacji wytrawiacza przystąpiono po 24 i 96 godz. od zmieszania proszku z wodą [25]. Badania przeprowadzone przez Camilleri [12] wykazały zmiany zarówno strukturalne, jak i chemiczne w materiale Biodentine po trwającym 20 s wytrawieniu $37 \%$ kwasem fosforowym w porównaniu z grupą kontrolną, której nie poddano działaniu wytrawiacza. W przypadku Biodentine po aplikacji wytrawiacza obserwowano niższy stosunek wapnia do krzemu oraz zmniejszenie wysokości piku przy chlorku w porównaniu z grupą kontrolną. Natomiast w obu grupach trawienie kwasem nie wpłynęło na mikrotwardość materiału. Elnaghy [26] ocenił wpływ kwasowości środowiska na parametry fizykomechaniczne Biodentine i białego MTA. Grupę I stanowiło 60 cylindrów wypełnionych Biodentine, natomiast grupę II - 60 cylindrów wypełnionych białym MTA. Każdą z grup podzielono na 4 podgrupy w zależności od pH środowiska (odpowiednio 7,4; 6,4; 5,4 i 4,4). Po upływie 7 dni próbki umyto i osuszono, a następnie poddano ocenie ich mikrotwardość i wytrzymałość na ściskanie. Wyniki wykazały, że mikrotwardość materiału Biodentine była znacząco wyższa w porównaniu z białym MTA we wszystkich podgrupach. Zaobserwowano również, iż spadek pH środowiska obniża mikrotwardość zarówno materiału Biodentine, jak i białego MTA. Wytrzymałość materiałów na ściskanie po ekspozycji na coraz niższe $\mathrm{pH}$ również ulega zmniejszeniu. $\mathrm{W}$ badaniu własnym użyto systemu samotrawiącego Prelude zgodnie z zaleceniami producenta. W grupie I system wiążący aplikowano po 15 min od przygotowania materiału Biodentine, natomiast w grupie II zabieg odroczono o 24 godz. W grupie I, po naniesieniu Prelude Primer, zaobserwowano, że w wyniku kontaktu tego preparatu z materiałem Biodentine powstawała zawiesina. W grupie II, po aplikacji Prelude Primer, nie obserwowano jakichkolwiek interakcji. Pojawienie się zawiesiny w grupie I może świadczyć o reakcji chemicznej zachodzącej pomiędzy primerem a materiałem Biodentine. W tym miejscu należy zaznaczyć, że primer ma odczyn kwasowy (pH ok. 2-3), a Biodentine zasadowy (pH ok. 12). Po upływie 24 godz. od przygotowania preparatu Biodentine nie obserwowano okiem nieuzbrojonym jakichkolwiek interakcji.

Trwałość wypełnienia ma istotny wpływ na powodzenia leczenia stomatologicznego i w dużej mierze zależy od wytrzymałości połączenia materiału z tkankami zęba. Badania laboratoryjne wykazały, że wytrzymałość połączenia jest wystarczająca 17-20 MPa [20, 27, 28]. Powszechnie do oceny ilościowej siły adhezji materiałów wypełniających do tkanek zęba wykorzystuje się metodę ścinania (shear bond strength - SBS) oraz metodę zrywania (microtensile bond strength - $\mu \mathrm{TBS}$ ). Metoda ścinania wymieniana jest również w metodologii badań nad materiałami na bazie krzemianu trójwapniowego [19, 20, 28,
29, 30]. Odobaș i wsp. [29] oceniali wytrzymałość połączenia materiału Biodentine z materiałem kompozytowym po zastosowaniu trzech różnych systemów wiążących. Do badania wykorzystali Prime\&Bond ${ }^{\circledR}$ NT (stosowany w technice total-etch), 2-etapowy samotrawiący Clearfil SE Bond oraz jedno-etapowy samotrawiący Clearfil S3 Bond. Oceny dokonywali po upływie 12 min oraz 24 godz. od przygotowania materiału Biodentine. Największą wytrzymałość połączenia (19,559 MPa) materiału Biodentine z materiałem kompozytowym obserwowali w przypadku systemu wiążącego Clearfil SE Bond po 24 godz. Najniższe wartości (9,127 MPa) zaobserwowali w grupie, w której zastosowano system Prime\&Bond ${ }^{\circledR}$ NT po 12 min od przygotowania Biodentine. Autorzy nie stwierdzili statystycznie istotnych różnic pomiędzy badanymi grupami po 12 min i 24 godz. Odmienne wyniki uzyskali Krawczyk-Stuss i wsp. [19] w badaniu oceniającym wytrzymałość połączenia Biodentine z materiałem kompozytowym w zależności od czasu aplikacji i rodzaju systemu wiążącego. Do badań użyto w grupie I systemu adhezyjnego IV generacji (Optibond ${ }^{\circledR} \mathrm{FL}$ ), w grupie II systemu adhezyjnego V generacji (Adper Single Bond $^{\circledR}$ ), a w grupie III samotrawiącego systemu VI generacji (Clearfil S3 Bond $^{\circledR}$ ). Po 12 min od rozrobienia materiału Biodentine największą wytrzymałość połączenia odnotowano dla samotrawiącego systemu Clearfil S3 Bond ${ }^{\circledR}$. Natomiast zarówno po 7 dniach, jak i po 28 dniach nie obserwowano statystycznie istotnych różnic w wytrzymałości połączenia. Cantekin i Avci [20] ocenili siłę wiązania kompozytów na bazie metakrylanów (Aelite All Purpose Body) i siloranów (Filtek Silorane) oraz konwencjonalnych cementów szkłojonomerowych (GC Fuji IX) z materiałem Biodentine i MTA. Badania przeprowadzili po całkowitym związaniu materiałów, dla Biodentine po upływie 15 min i po 96 godz. dla MTA. Najwyższą wartość zaobserwowali dla połączenia kompozytu na bazie metakrylanów z materiałem Biodentine (17,7 MPa), natomiast najniższą dla konwencjonalnego cementu szkłojonomerowego z MTA (5,8 MPa). Dla porównania wytrzymałość połączenia między materiałem MTA a kompozytem na bazie metakrylanów wynosiła 8,9 MPa. Niestety, autorzy nie podają, jakiego systemu wiążącego użyli w badaniu. Neelakantan i wsp. [31] zbadali wytrzymałość połączenia materiału kompozytowego z białym MTA po zastosowaniu rożnych protokołów adhezyjnych. Zwrócili szczególną uwagę na pH i rodzaj rozpuszczalnika użytego w systemie wiążącym. Natomiast Bayrak i wsp. [28] sugerują, iż rodzaj rozpuszczalnika oraz zawartość wypełniacza w systemie adhezyjnym może mieć większy wpływ na wartość wytrzymałości połączenia niż jego pH. Niskie pH systemu wiążącego przyczynia się do zmniejszenia wytrzymałości połączenia. Należy zwrócić uwagę, iż kwaśne środowisko dodatkowo może mieć negatywny wpływ na właściwości mechaniczne materiałów podkładowych.

\section{WNIOSKI}

Uzyskane wyniki sugerują, że materiał Biodentine po $15 \mathrm{~min}$ od przygotowania nie ulega związaniu w takim stopniu, by 
w przypadku użycia go jako podkładu można było bezpiecznie, tj. bez obawy interakcji, stosować system wiążący na zębinę i szkliwo. Odroczenie odbudowy korony zęba o 24 godz. wydaje się w zupełności wystarczające. Ocena wpływu zanieczyszczeń na połączenie odbudowy z tkankami zęba wymaga wykonania dodatkowych badań.

\section{PIŚMIENNICTWO}

1. Van Meerbeek B, De Munck J, Yoshida Y, Inoue S, Vargas M, Vijay P, et al. Buonocore memorial lecture. Adhesion to enamel and dentin: current status and future challenges. Oper Dent 2003;28:215-35.

2. Perdigão J. Dentin bonding as function of dentin structure. Dent Clin North Am 2002;46:1-25.

3. Swift EJ Jr. Dentin/enamel adhesives: review of literature. Pediatr Dent 2002;24:456-61.

4. Armstrong SR, Vargas MA, Fang Q, Laffoon JE. Microtensile bond strength of a total-etch 3-step, total-etch 2-step, self-etch 2-step, and a self-etch 1-step dentin bonding system through 15-month water storage. J Adhes Dent 2003;5:47-56.

5. Perdigão J, Geraldeli S. Bonding characteristics of self-etching adhesives to intact vs. prepared enamel. J Esthet Restor Dent 2003;15:32-42.

6. Sensi LG, Lopes GC, Monteiro S Jr, Banatieri LN, Vieira LC. Dentin bond strength of self-etching primers/adhesives. Oper Dent 2005;30:63-8.

7. Mazurek K. Adhezyjne cementowanie uzupełnień ceramicznych - kon dycjonowanie powierzchni biorących udział w łączeniu. Protet Stomatol 2014;64:216-22.

8. Lee SJ, Monsef M, Torabinejad M. Sealing ability of a mineral trioxide aggregate for repair of lateral root perforations. J Endod 1993;19: 541-4.

9. Parirokh M, Torabinejad M. Mineral trioxide aggregate: a comprehensive literature review. Part I: Chemical, physical, and antibacterial properties. J Endod 2010;36:16-27.

10. Torabinejad M, Parirokh M. Mineral trioxide aggregate: a comprehensive literature review. Part II: Leakage and biocompatibility investigations. J Endod 2010;36:190-202.

11. Parirokh M, Torabinejad M. Mineral trioxide aggregate: a comprehensive literature review. Part III: Clinical applications, drawbacks, and mechanism of action. J Endod 2010;36:400-13.

12. Camilleri J. Investigation of Biodentine as dentine replacement material. J Dent 2013;41:600-10.

13. Rajasekharan S, Martens LC, Cauwels RG, Verbeeck RM. Biodentine material characteristics and clinical applications: a review of the literature. Eur Arch Paediatr Dent 2014;15:147-58.

14. Bortoluzi EA, Broon NJ, Bramante CM, Felippe WT, Tanomaru Filho M, Esberard RM. The influence of calcium chloride on the setting time, solubility, disintegration, and $\mathrm{pH}$ of mineral trioxide aggregate and white Portland cement with a radiopacifier. J Endod 2009;35:550-4.
15. Malkondu Ö, Karapinar Kazandağ M, Kazazoğlu E. A review on Biodentine, a contemporary dentine replacement and repair material. BioMed Res Int 2014;2014:160951. doi: 10.1155/2014/160951.

16. Grech L, Mallia B, Camilleri J. Investigation of the physical properties of tricalcium silicate cement-based root-end filling materials. Dent Mater 2013;29:20-8.

17. Nowicka A, Lipski M, Postek-Stefańska L, Wysoczyńska-Jankowicz I, Lichota D, Sporniak-Tutak K, et al. Pokrycie bezpośrednie miazgi zębów stałych z użyciem preparatu Biodentine - doniesienie wstępne. Mag Stomatol 2012;22:30-7.

18. Koubi G, Colon P, Franquin JC, Hartmann A, Richard G, Faure MO, et al. Clinical evaluation of the performance and safety of a new dentine substitute, Biodentine, in the restoration of posterior teeth - a prospective study. Clin Oral Investig 2013;17:243-9.

19. Krawczyk-Stuss M, Ostrowska A, Łapińska B, Nowak J, Bołtacz-Rzepkowska E. Wytrzymałość połączenia Biodentine ze światłoutwardzalnym materiałem kompozytowym w zależności od czasu aplikacji i rodzaju systemu adhezyjnego. Dent Med Probl 2015;52:434-9.

20. Cantekin K, Avci S. Evaluation of shear bond strength of two resin-based composites and glass ionomer cement to pure tricalcium silicate-based cement (Biodentine). J Appl Oral Sci 2014;22(4):302-6.

21. Olek A, Cynkier J. Metody oceny połączenia materiałów złożonych z tkankami zęba - przegląd piśmiennictwa. Dent Med Probl 2011;48:86-96.

22. Perdigão J. New developments in dental adhesion. Dent Clin North Am 2007;51:333-57.

23. D'Arcangelo C, Vanini L, Prosperi GD, Di Bussolo G, De Angelis F, D'Amario M. The influence of adhesive thickness on the microtensile bond strength of the three adhesive systems. J Adhes Dent 2009;11:109-15.

24. Giuliani V, Nieri M, Pace R, Pagavino G. Effects of pH on surface hardness and microstructure of mineral trioxide aggregate and Aureoseal: an in vitro study. J Endod 2010;36:1883-6.

25. Kayahan M, Nekoofar M, Kazandağ M, Canpolat C, Malkondu O, Kaptan F, et al. Effect of acid-etching procedure on selected physical properties of mineral trioxide aggregate. Int Endod J 2009;42:1004-14.

26. Elnaghy AM. Influence of acidic environment on properties of Biodentine and White Mineral Trioxide Aggregate: a comparative study. J Endod 2014;40:953-7.

27. Al-Sarheed MA. Evaluation of shear bond strength and SEM observation of all-in-one self-etching primer used for bonding of fissure sealants. J Contemp Dent Pract 2006;7:9-16.

28. Bayrak S, Tunç ES, Saroğlu I, Eğilmez T. Shear bond strengths of different adhesive systems to white mineral trioxide aggregate. Dent Mater J 2009;28:62-7.

29. Odabaș ME, Bani M, Tirali RE. Shear bond strengths of different adhesive systems to Biodentine. Sci World J 2013;2013:626103. doi: $10.1155 / 2013 / 626103$.

30. Altunsoy M, Tanriver M, Ok E, Kucukyilmaz E. Shear bond strength of a self-adhering flowable composite and flowable base composite to mineral trioxide aggregate, calcium-enriched mixture cement, and Biodentine. J Endod 2015;41:1691-5.

31. Neelakantan P, Grotra D, Subbarao CV, Garcia-Godoy F. The shear bond strength of resin-based composite to white mineral trioxide aggregate. J Am Dent Assoc 2012;143:40-5. 